\title{
Assigning an '18' rating to movies with tobacco imagery is essential to reduce youth smoking
}

\author{
Christopher Millett, ${ }^{1}$ Stanton A Glantz ${ }^{2,3}$
}

Exposure to smoking in movies is a potent stimulus for youth smoking. ${ }^{1-4}$ In this issue of Thorax, (see page 417) McNeil et al document the occurrence of tobacco in the most commercially successful films released in the UK from 1989 to $2008 .^{5}$ While there is a decrease in the mean rate of tobacco episodes (which includes tobacco use, tobacco paraphernalia, inferred tobacco use, brand appearances) over time, $70 \%$ of the films had one or more tobacco episodes. Tobacco or tobacco-related products appeared in $68 \%$ of all youth-rated films (British Board of Film Classification (BBFC) rating '15' and below). More important, of the films from 2004 to 2008 that contained tobacco, 97\% were rated $\mathrm{BBFC} 15$ and lower and $73 \%$ were deemed suitable for those $<15$ years of age.

This continuing high level of exposure to smoking in films rated suitable for youth undermines efforts to reduce smoking among children and adolescents, not only in Britain but globally. Approximately one in five young teenagers (13-15 years) worldwide is a regular smoker with 80-100000 children taking up the habit every day. ${ }^{6}$ One in six 15 -year-old girls in England (17\%) and Scotland $(16 \%)$ were regular smokers in 2008, and the prevalence of smoking among 15-year-old boys in Scotland actually increased from $12 \%$ in 2006 to $14 \%$ in $2008 .^{89}$ Smoking prevalence and usage are highest among youth living in deprived areas. For example, 29\% of 15-year-old regular smokers living in the most

\footnotetext{
'Department of Primary Care and Public Health, Imperial College, London, UK; ${ }^{2}$ Division of Cardiology, University of California, San Francisco, California, USA; ${ }^{3}$ Center for Tobacco Control Research and Education, University of California, San Francisco, California, USA

Correspondence to Christopher Millett, Department of Primary Care and Public Health, School of Public Health, Imperial College, 3rd Floor, Reynolds Building, St Dunstan's Road, London W6 8RP, UK;

c.millett@imperial.ac.uk
}

deprived areas in Scotland reported smoking more than 70 cigarettes a week compared with only $12 \%$ in the most affluent areas. ${ }^{9}$

Concern about the impact of exposure to tobacco imagery in movies on youth smoking led the World Health Organization (WHO) to recommend that all future movies with scenes of smoking should be given an adult rating, with the possible exception of movies that reflect the dangers of tobacco use or that depict smoking by a historical figure who actually smoked. ${ }^{1}$ Implementing this policy would substantially reduce the dose of onscreen smoking delivered to children and adolescents and the corresponding response of smoking initiation.

Efforts to implement the WHO recommendations in the UK have been led by public health and community advocates in Liverpool, north-west England, where the prevalence of youth smoking and tobaccorelated harm are considerably higher than elsewhere in the country. Smoke-free Liverpool lobbied but failed to persuade the BBFC to faithfully apply its own rules for rating films that contain smoking. In particular, the BBFC's rules state that an 18 rating should be awarded to films "where material or treatment appears to the Board to risk harm to individuals or, through their behaviour, to society, ${ }^{10}$ a standard easily met by on-screen tobacco imagery given the proven causal relationship between this exposure and initiation and progression of smoking. The results of the study by McNeil et al clearly show that the BBFC has not been implementing its stated policy.

Because BBFC ratings are only advisory to local councils, in December 2008 advocates lobbied Liverpool City Council to apply an adult ('18') rating to films containing smoking within the local jurisdiction. The council undertook a 3month consultation on this proposal but declined to act during a full meeting on 9 December 2009, instead asking for more research directly relevant to England and Liverpool.

In this issue of Thorax, McNeil et al provide precisely the evidence that Liverpool seeks.

The stakes for British youth are very high in this debate. Studies from the USA estimate the attributable risk of smoking initiation associated with exposure to onscreen smoking. After controlling for a wide range of confounders, four studies in the USA have estimated the attributable risk fraction of adolescent and young adult smokers. ${ }^{11-14}$ A New England cohort $^{11}$ (middle school students at baseline) revealed that $0.52(95 \%$ CI 0.30 to 0.67) of those who 'tried smoking' was attributable to smoking in the movies. A later follow-up in the same cohort ${ }^{12}$ found an attributable risk fraction of 0.35 (95\% CI 0.14 to 0.56 ) for established smoking at young adulthood due to movie smoking exposure. A different northern New England longitudinal cohort ${ }^{13}$ that started with younger children (4th-6th graders at baseline) found that 0.46 (95\% CI 0.11 to $0.70)$ of youth who tried smoking was attributable to movie exposure. Finally, a national cross-sectional study ${ }^{14}$ (adolescents aged 10-14 years) found that the adjusted attributable fraction for having tried smoking was 0.38 (95\% CI 0.20 to $0.56)$. We pooled these four estimates (using Stata 10 metan) to obtain an overall attributable risk estimate of 0.44 (CI 0.34 to 0.58 ) and applied this pooled estimate to smoking prevalence estimates ${ }^{15}$ to estimate the number of current and ever smokers aged 11-15 years in Britain attributable to exposure to smoking in movies.

The prevalence of 11-15-year-olds whose ever smoking could be attributable to exposure to smoking in movies was $11.0 \%, 13.1 \%$ and $13.7 \%$ in England, Scotland and Wales. The respective prevalence figures for current smoking attributable to exposure to smoking in movies was $5.2 \%, 5.3 \%$ and $5.3 \%$. In 2006 the number of 11-15-year-olds whose ever smoking was attributable to exposure to smoking in movies was 350000, 41000 and 26000 in England, Scotland and Wales. The number whose current smoking was attributable to exposure to smoking in movies was 167000, 17000 and 10000 , respectively.

These estimates, while substantial, almost certainly underestimate the number of British youth who are smoking because of exposure to smoking in movies for two reasons. First, because the BBFC rates many US adult-content ' $\mathrm{R}$ ' films 
(under 17 not admitted without a parent) as appropriate for youth ('15' or lower), British youth are exposed to much higher doses of on-screen smoking than the American youth used to develop the attributable risks quoted above. Anderson et al found that, between 2001 and 2006, British youth were exposed to $28 \%$ more smoking impressions in UK youth-rated movies than American youth-rated movies because $79 \%$ of movies rated for adults in the USA (' $R$ ') were classified as suitable for youth in the UK. ${ }^{16}$ Second, Britain has strong restrictions on conventional advertising whereas the USA has few such restrictions. Thus, the relative importance of smoking in movies as a stimulant for adolescent smoking will be higher in Britain than in the USA

A new tobacco control strategy for England was published on 1 February 2010, a key objective of which is to 'stop the inflow of young people recruited as smokers' ${ }^{17}$ but then it timidly endorses current policy that merely recommends that smoking 'must not be featured in programmes made primarily for children (defined as $<15$ years of age) unless there is strong editorial justification' and smoking 'must not be condoned, encouraged or glamourised in other programmes likely to be widely seen or heard by under18s unless there is editorial justification'. There are two problems with these recommendations. First, it is like saying 'cigarette adverts should not appear in magazines primarily for children unless there is a strong editorial justification' and, second, there is no clear standard of what 'editorial justification' means.

In contrast, McNeil et al call for 'more rational application of BBFC classification, such as ensuring that smoking and other tobacco use be excluded from all youthrated films (BBFC U, PG, 12/12A and 15)' with very limited specific exceptions, as the WHO has recommended. We agree with McNeil et al. Ensuring that the BBFC faithfully implements its stated policy and rates movies containing smoking are unambiguously assigned a rating of ' 18 ' would be the simplest and least expensive way to achieve this important goal.

Failing rapid and effective action at the national level, Liverpool and other local councils should exercise their authority to protect their youth from tobacco promotions embedded in films.

Acknowledgements Data from the Health Behaviour in School-Aged Children: WHO Collaborative Cross-National Study (HBSC) 2005/2006 Survey were supplied by agreement with HBSC Principal Investigators in Scotland (Candace Currie), England (Antony Morgan) and Wales (Chris Roberts).

Funding SAG is American Legacy Foundation Distinguished Professor in Tobacco Control. $\mathrm{CM}$ is part funded by the Higher Education Funding Council for England.

\section{Competing interests None.}

Provenance and peer review Commissioned; not externally peer reviewed.

Thorax 2010;65:377-378

doi:10.1136/thx.2009.133108

\section{REFERENCES}

1. World Health Organization. Smoke free movies: from evidence to action. 2009. http://www.who.int/ tobacco/smoke free movies/en/index.html (accessed 31 Dec 2009).

2. BMA Board of Science. Forever cool: the influence of smoking imagery on young people. London: British Medical Association, 2008. http://www.bma.org.uk/ health promotion ethics/tobacco/forevercool.jsp (accessed 5 Jan 2010).

3. Institute of Medicine. Ending the tobacco problem: a blueprint for the Nation. Washington, DC: National Academies Press, 2007.

4. National Cancer Institute. Tobacco control monograph 19: the role of the media in promoting and reducing tobacco use. Bethesda, MD: US National Cancer Institute, 2008.
5. McNeil A, Chen Y, Britton J, et al. Tobacco and tobacco branding in films most popular in the UK from 1989 to 2008. Thorax 2010;65:417-22.

6. The Global Youth Tobacco Survey Collaborative Group. Tobacco use among youth: a cross country comparison. Tob Control 2002;11:252-70

7. Smoking Statistics. Regional office for the Western Pacific. Geneva: World Health Organization. http:// www.wpro.who.int/media centre/fact sheets/ fs 20020528.htm (accessèd 30 Dec 2009).

8. National Health Service. Smoking, drinking and drug use among young people in England in 2008. London: NHS Information Centre for Health and Socia Care. http://www.ic.nhs.uk/pubs/sdd08fullreport (accessed 30 Dec 2009).

9. Scottish schools adolescent lifestyle and substance use survey (SALSUS)—National report 2008. http:// www.drugmisuse.isdscotland.org/publications/local/ SALSUS 2008.pdf (accessed 30 Dec 2009).

10. British Board of Film Classification. BBFC '18' - suitable only for adults. London: BBFC, 2009. http://www.bbfc.co.uk/downloads/pub/Guidelines/ BBFC\%20Classification\%20Guidelines\%202009.pdf (accessed 31 Dec 2009).

11. Dalton MA, Sargent JD, Beach ML, et al. Effect of viewing smoking in movies on adolescent smoking initiation: a cohort study. Lancet 2003;362:281-5.

12. Dalton MA, Beach ML, Adachi-Mejia AM, et al. Early exposure to movie smoking predicts established smoking by older teens and young adults. Pediatrics 2009; 123:e551-8.

13. Titus-Ernstoff $\mathbf{L}$, Dalton MA, Adachi-Mejia AM, et al. Longitudinal study of viewing smoking in movies and initiation of smoking by children. Pediatrics 2008; 121:15-21.

14. Sargent JD, Beach ML, Adachi-Mejia AM, et al. Exposure to movie smoking: its relation to smoking initiation among US adolescents. Pediatrics 2005;116:1183-91.

15. World Health Organization. Health behaviour in school-aged children: WHO collaborative crossnational study (HBSC) 2005/2006 survey. Geneva: World Health Organization, 2006.

16. Anderson S, Millett C, Polansky J, et al. Exposure to smoking in movies among British adolescents 20012006. Tob Control 2010 Mar 2 [Epub ahead of print] doi:10.1136/tc.2009.03491

17. Department of Health. A smokefree future: a comprehensive tobacco control strategy for England. London: Department of Health. http://www.dh.gov. uk/en/Publicationsandstatistics/Publications/ PublicationsPolicyAndGuidance/DH 111749 (accessed 1 Feb 2010). 


\section{REFERENCES}

1. Anderson SD. Exercise-induced asthma. In: Kay AB, ed. Allergy and allergic diseases. Oxford: Blackwell Scientific Publications, 1997:672-711.

2. Rundell KW, Im J, Mayers LB, et al. Self-reported symptoms and exercise-induced asthma in the elite athlete. Med Sci Sports Exerc 2001; 33:208-13.

3. Dickinson JW, Whyte GP, McConnell AK, et al. Midexpiratory flow versus FEV1 measurements in the diagnosis of exercise induced asthma in elite athletes. Thorax 2006;61:111-4.

4. Holzer K, Douglass JA. Exercise induced bronchoconstriction in elite athletes: measuring the fall. Thorax 2006;61:94-6.

5. Parsons JP, Mastronarde JG. Exercise-induced bronchoconstriction in athletes. Chest 2005;128:3966-74.

\section{Corrections}

doi:10.1136/thx.2009.122291 corr1

Conway Morris A, Kefala K, Wilkinson $\mathrm{TS}$, et al. Diagnostic importance of pulmonary interleukin-1b and interleukin-8 in ventilator-associated pneumonia. Thorax 2010;65:201-7. This article should have included the note that Dr Kefala was joint first author.
Polverino E, Dambrava P, Cilloniz C, et al. Nursing home-acquired pneumonia: a 10 year single-centre experience. Thorax 2010;65:354-59. The correct affiliation for affiliation 1 should have read "Respiratory Department, Hospital Clinic-IDIBAPS, Barcelona-Spain, Centro de Investigación Biomedica En RedEnfermedades Respiratorias (CibeRes, CB06/06/0028, el Ciberes es una iniciativa del ISCIII) - 2009SGRO http://www.idibapsrespiratoryresearch. org."

doi:10.1136/thx.2009.133108corr1

Millett C, Glantz SA. Assigning an '18' rating to movies with tobacco imagery is essential to reduce youth smoking. Thorax 2010;65:377-8. The authors referred to a paper by McNeil et al; this should have been Lyons et al (Lyons A, McNeill A, Chen Y, et al).
Lyons A, McNeill A, Chen Y, et al. Tobacco and tobacco branding in films most popular in the UK from 1989 to 2008. Thorax 2010;65:417-22. There is an error in figure legend 2 which currently reads "Trends in all tobacco intervals and tobacco use intervals per hour per day by British Board of Film Classification (BBFC) category (all figures expressed as means)." It should have read: "Trends in all tobacco intervals and tobacco use intervals per hour per year by British Board of Film Classification (BBFC) category (all figures expressed as means)."

doi:10.1136/thx.2009.127274corr1

Kemp SV, El Batrawy SH, Harrison RN, et al. Learning curves for endobronchial ultrasound using cusum analysis. Thorax 2010;65:534-8. The author name A Roselli should have read A Rosell. 